\title{
UPAYA PENANGGULANGAN KENAKALAN PESERTA DIDIK DI MADRASAH TSANAWIYAH NEGERI SUNGAYANG KABUPATEN TANAH DATAR
}

\author{
Yulmawati \\ Guru MTs Negeri Sungayang \\ J I. Sawah Parit, Sungayang, Kabupaten Tanah Datar
}

$+20$

\begin{abstract}
Based on the achievements of State Islamic Secondary School Sungayang it also had many violations were done by student as seen in the students' case book in the academic year 2015/2016. The violation was only related to discipline, but it prohibits the school's progress. This research was aimed at describing the response of State Islamic Secondary School Sungayang toward students' delinquency. This study was qualitative case study by applying observation, interview and documentation as instruments on collecting data. The primary data in this study were Vice Head of Students, Guidance and Counseling Teacher and students. The results revealed that the efforts to tackle students' delinquency was understanding the forms of delinquency committed by students. There were high, medium and low delinquency. The students' delinquency might come from family and school factor. The efforts on overcoming studetns delinquency were preventive, curative and rehabilitation. On the preventive, the school did socialization to the parent and the community. On the curative, the school gave the punishment based on the type of delinquency. On the rehabilitation, the school did direction and education of a noble human being. While the obstacles encountered were many parents ignore their children; the rule did not correspond to the current situation; and the students nowadays at the age of transition of delinquency.
\end{abstract}

Keywords: The Students' Delinquency, State Islamic Secondary School, Sungayang, Tanah Datar

\section{PENDAHULUAN}

Madrasah Tsanawiyah Negeri Sungayang adalah satu-satunya MTs Negeri yang berada di Kecamatan Sungayang dan juga madrasah yang sudah terakreditasi A dan diminati oleh masyarakat. Berbagai prestasi yang sudah diraih oleh MTs Negeri Sungayang baik oleh Kepala Madrasah, guru maupun peserta didik, di antaranya adalah juara III pada lomba kompetisi kepala berprestasi tingkat nasional, (Studi Dokumentasi pada Website Resmi MTs Negeri Sungayang, Rabu, 2 September 2015). Begitu juga prestasi yang diraih oleh majlis guru dan peserta didik sebagaimana hasil wawancara yang peneliti lakukan pada tanggal 30 Desember 2015 dengan wakil bidang kesiswaan MTs Negeri Sungayang. Adapun prestasi yang berhasil diraih tersebut 
di antaranya adalah juara II Tk. Provinsi lomba Kompetisi Sains Madrasah (KSM) oleh Kasih Sabdatul Hikmah, juara III lomba Kreasi Majalah Dinding Tk. Provinsi Aliya. dkk, Juara II lomba Bintang Qasidah Tk. Kabupaten oleh Wangi Rahmadhani, Juara I lomba guru berprestasi Tk. Kabupaten Yusrizal, M.Pd dan Juara II guru berprestasi Tk. Kabupaten Andrizal, M.Pd dan lainlain (Studi Dokumentasi Catatan Prestasi Madrasah Tahun 2015). Selanjutnya peneliti juga mendapatkan informasi dari Kepala Madrasah, karena banyaknya prestasi tersebut dan juga didukung oleh sarana prasarana yang memadai pada saat ini MTs Negeri Sungayang juga merupakan salah satu madrasah yang dijadikan pilot project di antara enam madrasah lainnya di Kabupaten Tanah Datar.

Berdasarkan observasi awal peneliti (Tanggal 30 Desember 2015), dibalik prestasi yang diraih oleh MTs Negeri Sungayang juga terjadi berbagai pelanggaran yang dilakukan oleh peserta didik terhadap tata tertib yang diberlakukan di MTs Negeri Sungayang yang terlihat dalam buku kasus siswa oleh Guru Bimbingan dan Konseling Tahun Pelajaran 2015/2016. Pelanggaran tersebut seperti datang terlambat, tidak hadir tanpa keterangan, berpakaian tidak rapi (celana pensil), rambut panjang bagi laki-laki, keluar masuk ketika jam pelajaran berlangsung, sering tidak membuat tugas yang diberikan guru, merokok, bolos, ke warnet, berkelahi dan terpengaruh oleh pergaulan muda-mudi.

Berdasarkan hal tersebut menurut peneliti kajian tentang upaya penanggulangan kenakalan peserta didik di MTs Negeri Sungayang penting untuk diteliti. Adapun yang peneliti maksud dengan kenakalan peserta didik di sini adalah pelanggaran terhadap tata tertib yang diberlakukan di MTs Negeri Sungayang.

\section{METODE PENELITIAN}

Penelitian ini menggunakan desain kualitatif dengan metode studi kasus (case study). Menurut Yin (1994) studi kasus adalah "the case study is a research method that arises to understand the complex nature of social phenomena, in the context of real life" yaitu metode penelitian yang muncul untuk memahami sifat kompleks dari fenomena sosial, dalam konteks kehidupan nyata (Anward, 2014). Penelitian ini mengungkap tentang upaya menanggulangi kenakalan peserta didik di MTs Negeri Sungayang.

Pengumpulan data dalam penelitian ini dilakukan dengan cara penelitian lapangan yaitu terjun langsung ke lokasi penelitian untuk mendapatkan data yang diperlukan. Adapun teknik pengumpulan data yang peneliti gunakan dalam penelitian ini adalah observasi, wawancara dan dokumentasi. 


\section{Observasi (Observation)}

Margono (2005) mengungkapkan bahwa observasi adalah pengamatan dan pencatatan secara sistematis terhadap gejala yang tampak pada objek penelitian (Satori dan Komariah, 2009). Observasi yang peneliti lakukan dalam penelitian ini mengamati langsung kondisi obyektif tentang kenakalan peserta didik serta upaya dalam menanggulangi kenakalan tersebut.

\section{Wawancara (Interview)}

Esterberg (2002) mendefenisikan interview adalah "a meeting of two persons to exchange information and idea through question and responses, resulting in communication and joint constrcuction of meaning about particular topic" (Satori dan Komariah, 2009). Wawancara adalah pertemuan dua orang untuk bertukar informasi dan ide melalui tanya jawab, sehingga dapat dikonstruksikan makna dalam suatu topik tertentu.

Wawancara yang peneliti gunakan adalah wawancara tidak terstruktur, yaitu wawancara bebas di mana peneliti tidak menggunakan pedoman wawancara yang telah tersusun secara sistematif dan lengkap untuk pengumpul datanya (Sugiyono, 2007). Pedoman wawancara hanya garis-garis besar permasalahan yang akan ditanyakan.

\section{Dokumentasi}

Dokumentasi merupakan teknik yang digunakan untuk mengumpulkan data yang diperlukan dari sumber berupa dokumen tertulis (kalau ada) yang berkaitan dengan usaha madrasah dalam menanggulangi kenakalan peserta didik. Sumber data dari penelitian ini adalah Kepala Madrasah, Wakil kepala bidang kesiswaan, guru bimbingan konseling, wali kelas serta peserta didik yang terlibat dengan kenakalan. Data dalam penelitian ini adalah data tentang kenakalan peserta didik di MTs Negeri Sungayang.

Analisis data peneliti lakukan dengan jalan bekerja dengan data, mengorganisasikan data, memilah-milahnya menjadi satuan yang dapat dikelola. Kemudian mengsintesiskannya, mencari dan menemukan pola, menemukan apa yang penting dan apa yang dipelajari dan memutuskan apa yang dapat diceriterakan kepada orang lain.

\section{HASIL PENELITIAN DAN PEMBAHASAN}

\section{Bentuk-Bentuk Kenakalan yang Dilakukan oleh Peserta Didik di MTs Negeri Sungayang}

Berdasarkan dari hasil wawancara peneliti dengan guru Bimbingan dan Konseling MTs Negeri Sungayang pada tanggal 15 Januari 2016, bentuk-bentuk kenakalan peserta 
didik di MTs Negeri Sungayang adalah pelanggaran terhadap tatatertib peserta didik. Beliau mengungkapkan bahwa pelanggaran yang dilakukan oleh peserta didik digolongkan kepada 3 bentuk sebagai berikut.

\section{a. Pelangaran Ringan}

Bentuk pelanggaran ringan yang sering dilakukan peserta didik pada umumnya masalah kerapian yaitu baju yang tidak dimasukkan, kaos kaki yang tidak sewarna, tidak memakai topi, rambut panjang, kuku panjang, memakai asesoris yang berlebihan dan memakai pakaian yang tidak sesuai dengan hari belajar, terlambat datang ke madrasah, dan keluar pekarangan tanpa izin. Selanjutnya dalam tata tertib peserta didik sudah disebutkan bahwa semua itu dilarang untuk dilakukan oleh peserta didik, namun sebagian peserta didik tetap melakukan pelanggaran.

\section{b. Pelanggaran Sedang}

Bentuk-bentuk pelanggaran sedang yang sering dilakukan oleh peserta didik yaitu berkaitan dengan tingkah laku peserta didik yang tidak seharusnya, misalnya berkata-kata kotor, berkelahi, merokok, bolos, corat-coret di dinding, meja, kursi, pintu dan tidak hadir berturut-turut selama 3 hari.

\section{c. Pelanggaran Berat}

Guru bimbingan dan konseling mengungkapkan pelanggaran berat yang tergolong dalam tata tertib adalah membawa handphone, melakukan amoral. Pelanggaran yang tergolong pada bentuk ini jarang sekali terjadi. Pelanggaran yang dimaksud yang pernah dilakukan peserta didik adalah membawa handphone ke madrasah.

Pada waktu yang sama hasil wawancara peneliti dengan seorang guru sebagai wali kelas dari peserta didik yang bermasalah mengungkapkan bahwa kenakalan peserta didik yang melakukan pelanggaran pada umumnya tergolong kepada pelanggaran ringan seperti mengganggu teman ketika belajar, tidak mau buat tugas yang diberikan oleh guru, keluar masuk ketika jam pelajaran. Pernyataan ini juga senada dengan ungkapan wakil kepala bidang kesiswaan yang penulis wawancarai pada tanggal 4 Januari 2016 bahwa peserta didik yang yang melakukan pelanggaran tidak begitu banyak, hanya sekitar $10 \%$ dan itupun hanya berbentuk pelanggaran ringan.

Ketika penulis mewawancarai beberapa orang peserta didik yang melakukan kenakalan (pelanggaran terhadap tata tertib) tentang pengetahuannya terhadap tata tertib tersebut, semua mereka menjawab mereka 
mengetahui hal itu namun perilaku itu tetap dilakukannya. Hal ini menandakan bahwa peserta didik melakukan kenakalan seperti itu dalam kondisi yang sadar atau sepengetahuannya, hanya saja karena suatu sebab mereka berbuat demikian.

Hasil temuan ini di dukung oleh penelitian Suprapti (2011) yang mengungkapkan bahw bentuk-bentuk kenakalan yang dilakukan oleh siswa tersebut adalah (1) memukul teman, (2) menonyol kepala teman, (3) merusak lingkungan dan sarana sekolah yaitu mencoret-coret meja dan tembok sekolah, (4) membawa dan mengonsumsi rokok di lingkungan sekolah, (5) berbicara tidak sopan kepada teman, (6) tidak kembali ke kelas/sekolah setelah minta ijin keluar, (7) terlambat masuk sekolah/kelas, (8) baju tidak dimasukkan kedalam celana, (9) atribut pakaian tidak lengkap, (10) membuat gaduh di kelas, (11) tidak mengerjakan tugas, dan (12) bermain handphone ketika KBM.

Jika dibandingkan penelitian Suprapti (2011) dengan penelitian yang dilakukan di MTs Negeri Sungayang memiliki persamaan dan perbedaan. Keduanya membahas permasalahan kenakalan siswa dan bentukbentuk kenakalan tersebut. Hanya saja penelitian yang dilakukan oleh Suprapti (2011) menggambarkan bentuk-bentuk kenakalan siswa secara global. Sementara penelitian yang dilakukan di MTs Negeri
Sungayang membagi bentuk kenakalan peserta didik kepada 3 bentuk yaitu pelanggaran ringan, sedang dan ringan.

\section{Faktor-faktor Penyebab Kenakalan Peserta Didik di MTs Negeri Sungayang}

Hasil wawancara dengan Wakil Kesiswaan pada tanggal 4 Januari 2016, faktor-faktor penyebab kenakalan peserta didik adalah pengaruh lingkungan, masyarakaat, internet, televisi, dan lingkungan sekolah, dan yang paling mempengaruhi adalah pengaruh teman sebaya. Selanjutnya hasil wawancara peneliti dengan guru bimbingan dan konseling pada tanggal 15 Januari 2016, faktor-faktor penyebab kenakalan peserta didik adalah 1) lingkungan keluarga kurang harmonis, di mana orang tua sibuk dengan pekerjaannya dan anak sibuk dengan dunianya sendiri, intinya kurangnya perhatian dari orang tua; 2) siswa susah membendung perkembangan dirinya yang dipengaruhi oleh usianya yang berada dalam masa panca roba; 3) pengaruh lingkungan apakah itu lingkungan keluarga, sekolah maupun masyarakat; dan 4) aturan madrasah.

Setelah ditanyakan langsung kepada beberapa orang peserta didik, di antara mereka banyak yang menjawab kenakalan peserta didik berasal dari lingkungan masyarakat, lingkungan keluarga, dan pengaruh temannya. Hal ini sama dengan 
hasil penelitian yang dilakukan oleh Ellonen (2008) yang menyatakan bahwa kenakalan remaja juga dipengaruhi oleh lingkungan masyarakat tempat peserta didik yang bersangkutan tinggal. Sadestrom (2008) juga menyatakan dalam hasil penelitiannya bahwa kenakalan peserta didik bersumber pengaruh teman sebaya baik itu di sekolah maupun di luar sekolah. Berarti ada persamaannya dengan penelitian yang di adakan di MTs Negeri Sungayang, karena kenakalan yang dilakukan oleh peserta didik karena adanya pengaruh dari teman baik di dalam madrasah maupun di luar madrasah.

Menurut Ngale (2009) dalam hasil penelitiannya bahwa kenakalan remaja (peserta didik) dipengaruhi oleh lingkungan kelurga. Terdapat persamaan dengan penelitian yang dilakukan di MTs Negeri Sungayang bahwa kenakalan peserta didik juga berasal dari lingkungan keluarganya.

\section{Upaya MTs Negeri Sungayang Menanggulangi Kenakalan Peserta Didik}

Upaya dalam menanggulangi kenakalan peserta didik dilaksanakan secara preventive (pencegahan), represive (mengahambat), maupun yang bersifat kuratif (penyembuhan) dan rehabilitasi (perbaikan). Penanganan kenakalan peserta didik tersebut dilakukan agar kenakalan peserta didik tersebut tidak terulang kembali.
Berdasarkan hasil wawancara peneliti (4 Januari 2016) dengan guru bimbingan konseling, upaya preventive kenakalan peserta didik dengan memberikan sosialisasi tata tertib yang akan diberlakukan terutama kepada peserta didik baru (kelas VII). Apabila perbuatan tersebut sudah terjadi, madrasah memberikan sanksi-sanksi ringan yang sifatnya mendidik.

Selain itu adalagi upaya preventif yang dilakukan, berdasarkan hasil wawancara (4 Januari 2016) dengan wakil kesiswaan adalah dengan mengadakan pembinaan melalui kegiatan ekstrakurikuler, mengadakan pembinaan oleh penasehat akademik, bekerjasama dengan wali kelas dan guru bimbingan konseling yang dikenal dengan "binsalia" (bimbingan insan mulia). Kesemua itu tidak terlepas dari kerja sama dan kontrol dari orang tua peserta didik.

Wakil Kesiswaan juga menegaskan bahwa dengan adanya kegiatan-kegiatan ekstrakurikuler peserta didik akan tumbuh menjadi seorang yang bertanggung jawab. $\mathrm{Hal}$ ini sejalan dengan hasil penelitian yang dilakukan oleh Guest dan McRee (2009) bahwa kegiatan ekstrakurikuler yang diikuti oleh peserta didik di madrasah dapat menjadi wadah bagi peserta didik untuk menyalurkan bakat, minat yang dimiliki peserta didik. Apabila peserta didik sudah disibukkan dengan kegiatan-kegiatan 
yang baik, yang penuh bimbingan dan pembinaan, kemungkinan-kemungkinan peserta didik akan melakukan pelanggaran (kenakalan) akan dapat ditolerir dengan baik.

Dari penelitian di atas terdapat persamaan dan perbedaan dengan hasil penelitian di MTs Negeri Sungayang. Persamaannya adalah kedua penelitian samasama membahas tentang upaya yang dapat dilakukan untuk mengurangi kenakalan peserta didik salah satunya melalui kegiatan ekstrakkurikuler. Perbedaannya adalah dalam penelitian ini peserta didik yang ikut dalam kegiatan ekstrakurikuler mendapatkan pembinaan dari pembina akademik, wali kelas, guru bimbingan dan konseling dan bekerjasama dengan orang tua peserta didik. sedangkan pada penelitian Guest dan McRee (2009) tidak dijelaskan.

Hasil wawancara peneliti dengan wakil kesiswaan, guru bimbingan dan konseling dan wali kelas, upaya preventif lain yang dilakukan pihak madrasah dalam menangani kenakalan peserta didik adalah dengan meningkatkan efektifitas hubungan orang tua dan madrasah. Hubungan orang tua dengan madrasah merupakan salah satu yang sangat diharapkan dalam membentuk karakter peserta didik. Meningkatkan hubungan madrasah dengan orang tua merupakan upaya preventif yang efektif dalam mencegah terjadinya kenakalan peserta didik di luar madrasah. Hal ini senada dengan penelitian Hoffmann dan Dufur (2008) yang menunjukan bahwa lingkungan keluarga dapat menjadi sumber kenakalan bagi remaja. karena kurangnya perhatian dan kasih sayang yang diberikan oleh orang tua kepada anaknya, anak akan mudah terjerumus kepada ke kenakalan.

\section{Hambatan yang Dialami oleh Madrasah dalam Menanggulangi Kenakalan Peserta Didik di MTs Negeri Sungayang.}

Wawancara peneliti (4 Januari 2016) dengan guru bimbingan dan konseling, hambatan yang dialami madrasah dalam menanggulangi kenakalan peserta didik adalah tidak adanya jam khusus yang tersedia untuk memberikan bimbingan dan konseling kepada peserta didik, sehingga pembinaan kepada peserta didik tidak tercapai sebagai mana yang diharapkan. Apalagi bagi peserta didik yang mau tamat, jam pelajarannya yang begitu padat.

Di samping itu guru bimbingan dan konseling juga menambahkan (4 Januari 2016) hambatan lain yang dialami madrasah dalam menanggulangi kenakalan peserta didik adalah kurangnya perhatian dan kerja sama antara orang tua dengan madrasah. karena ada sebahagian orang tua yang selalu sibuk dengan pekerjaannya, tidak 
mengindahkan dan tidak mau tau dengan permasalahan yang terjadi pada anak mereka.

\section{KESIMPULAN}

Pelanggaran yang dilakukan oleh peserta didik di MTs Negeri Sungayang digolongkan kepada 3 bentuk yaitu pelanggaran ringan, sedang dan ringan. Faktor-faktor penyebab kenakalan peserta didik adalah 1) lingkungan keluarga kurang harmonis; 2) siswa susah membendung perkembangan dirinya yang dipengaruhi oleh usianya yang berada dalam masa panca roba; 3 ) pengaruh lingkungan apakah itu lingkungan keluarga, sekolah maupun masyarakat; dan 4) aturan madrasah. Upaya MTs Negeri Sungayang dalam menanggulangi kenakalan peserta didik dilaksanakan secara preventive (pencegahan), represive (mengahambat), maupun yang bersifat kuratif (penyembuhan) dan rehabilitasi (perbaikan). Hambatan yang dialami MTs Negeri Sungayang dalam menanggulangi kenakalan peserta didik adalah tidak adanya jam khusus yang tersedia untuk memberikan bimbingan dan konseling kepada peserta didik

\section{KEPUSTAKAAN ACUAN}

Anward, Heryati Hemy. (2014). "The Diversity of Delinquency Behaviors and Causal Factors: A Study Juvenile Delinquences in Batulicin-Tanah Bumbu
Regency, South Kalimantan Province”. International Conference on Economics, Education and Humanities (ICEEH,14) Dec. 10-11, 2014 Bali (Indonesia).

Ellonen, Noora. (2008). "Adolescent Delinquency and Social Control in Finnish Schools: A Multilevel Analysis". Journal of Scandinavian Studies in Criminology and Crime Prevention. Vol 9, $p$ p 47-64, 2008

Guest, Andrew M. dan McRee, Nick. (2009). "A School-Level Analysis of Adolescent Extracurricular Activity, Delinquency, and Depression: The Importance of Situational Context". J Youth Adolescence 38:51-62.

Hoffmann, John P. dan Dufur, Mikaela J. (2008). "Family and School Capital Effects on Delinquency: Substitutes or Complements?" Sociological Perspectives, Vol. 51, Issue 1, pp. 29-62.

Ngale, Fritz. (2009). "Family Structure and Juvenile Delinquency Correctional Centre Betamba, Centre Province of Cameroon”. Int. J. of Delinquency. Vo. 10: 14-26, 2009.

Satori, Djam'an dan Komariah, Aan. (2009). Metode Penelitian Kualitatif. Bandung: Alfabeta. 
Soderstrom, Irina. (2008). "Theoretical Suprapti, Zikenia. (2011). Mengatasi

Predictors of Delinquency in and Out of

School among a Sample of Rural Public

School" Youth Southern Rural Sociology. 23(2), 2008, pp.135-156.

Sugiyono. (2007). Metode Penelitian

Pendidikan. Bandung: Alfabeta
Kenakalan Remaja Siswa Broken Home melalui Konseling Realita Di SMA Negeri 4 Pakalongan. Pekalongan: Skripsi STAIN Pekalongan. 